\title{
Science as a cultural construct
}

Sir - In the days of sound-bite epistemology, I should not be surprised that Gottfried and Wilson ${ }^{1}$ characterize my book, Constructing Quarks, by two short and decontextualized quotations from the last two paragraphs of a text which is 415 pages long (not counting a 43-page bibliography, most of it citations to the high-energy physics (HEP) literature $)^{2}$. One unfortunate consequence is that readers might imagine that there are no argumentative connections linking my "preposterous conclusions" to the historical substance of my book - which Gottfried and Wilson concede "displays a solid command of the developments that led to the Standard Model" and covers the "transition from the 'old' to the 'new' physics ... very well indeed", and which Gottfried has elsewhere generously described as "a superb account"3. I do have some arguments, however.

Gottfried and Wilson assert as selfevident that (a) the old and new physics were of "objectively unequal merit", implying that (b) this was the reason that the latter eclipsed the former. In regard to (a), I show in Constructing Quarks that this was a matter for legitimate dispute. One can argue that the standard model fits some philosophical criteria for theory-choice better than the theories and models of the old physics, but conversely one can argue that the old physics had the merit of explaining almost all of the phenomena that appear in the HEP laboratory. Newphysics data are terribly rare, and become visible only when an overwhelming 'background' of old-physics events is excluded from the analysis. Point (b) I believe to be historically untrue. In my historical research, I interviewed more than a hundred leading high-energy physicists and studied the published and unpublished literature extensively, and, in all honesty, that evidence did not persuade me that "objective merit" (as defined by Gottfried and Wilson) was what induced most physicists to move from one domain of knowledge and practice to the other. More positively, the same evidence did persuade me that such shifts could be easily understood in terms of what I called the dynamics of practice, relating research trajectories to the prior expertise of the physicists involved, symbiotic circuits of experimental and theoretical practice and so on. Much of Constructing Quarks is devoted to exemplifying that point; it is one of the links from the history to my "preposterous" conclusions; and neither Gottfried and Wilson, nor any other particle physicist, has ever disputed the adequacy of that aspect of my book.

The other critical thread that runs through Gottfried and Wilson's essay concerns the issue of prediction in science. They accuse me of assuming "the power to stop the clock at an arbitrary point, thereby ignoring subsequent evidence as to whether some bandwagon fell off the cliff or stayed on track". The term bandwagon does not figure in my interpretive lexicon, but there is a grain of irrelevant truth to that quotation. I handed over the final manuscript of Constructing Quarks in midJuly 1983 (immediately after my daughter Lucy was born), so I could not, for example, follow the story of the discovery of the $\mathrm{W}$ and $\mathrm{Z}$ particles very far (though I did my best: see the long footnote 44, 379-380, dated July 1983). But I did follow similarly important stories that had moreor-less run their course before paternity took over - scaling, the weak neutral current, charmed particles (see also my other publications expanding on these topics: copies available on request). And for those discoveries I argued in detail, again, that my model of the dynamics of practice fitted the historical evidence better than simple assertions that 'we got it right'. If Gottfried and Wilson want to challenge my specific accounts and interpretations of those events, I would be happy to argue with them. Failing that, it seems reasonable to regard their invocation of the Ws and Zs as a red herring.

One last remark. Gottfried and Wilson read into Constructing Quarks the sceptical message that "science is only a communal belief system with a dubious grip on reality". But the message was not sceptical: I defy anybody to find textual warrant for either the "only" or the "dubious" in that quotation. Like many scientists (and philosophers), Gottfried and Wilson assume that Constructing Quarks asserts the opposite of their stock image of science, but this is just a mistake. Over the past fourteen years I have explored more deeply the engagement of science with its object, the material world; for that, see my latest book, The Mangle of Practice ${ }^{4}$. But nothing there contradicts what I wrote in Constructing Quarks.

Andrew Pickering

Department of Sociology and Unit for

Criticism and Interpretive Theory,

University of Illinois

at Urbana-Champaign,

326 Lincoln Hall,

702 South Wright Street,

Urbana, Illinois 61801, USA

e-mail:pickerin@uiuc.edu
Sir — During its first quarter-century, discussion of the sociology and history of scientific knowledge (SSK) was largely restricted to social scientists. We welcome the growth of interest from natural scientists, especially as the most recent contributions represent a move towards serious debate.

We think we are still divided by rivers of misunderstanding, but at least they are no longer oceans. We can now see the possibility of building bridges. On our side we are beginning to see that our way of putting things, conditioned by 25 years of debate within the social sciences, might give natural scientists cause for concern. At the same time, we seem to be making progress in showing that most of this concern is misplaced. We will content ourselves in this letter by trying to clarify a few points.

Those who describe themselves as sociologists of scientific knowledge agree about most things. There are minor 'philosophical' disagreements between those who were first trained at Edinburgh and others, such as us, but the case-studies that emerge under the SSK label are virtually indistinguishable. 'SSK' is the most useful description for the group who consider that the core of the subject is careful, sociologically informed casestudies of experimentation and theory building.

SSK does not try to compete with natural science in the establishment or evaluation of scientific findings. We are social scientists and we do not think that evaluation of scientific findings is our business except in special circumstances; such circumstances have not arisen in this debate.

Because we are not in the business of evaluating scientific findings, we think it would be wrong of us to offer a running assessment of the pieces of scientific knowledge we discuss. Gottfried and Wilson suggest that when we discuss some scientific finding we should keep the reader up to date with the latest developments in the field.

It is as though they would argue that a historical study of what made people give up phlogiston and take up the idea of oxygen would be flawed unless it referred to the way oxygen is presented in the periodic table, used by divers and welders, and saves lives in hospitals. We are concerned with what caused changes in view before things were thoroughly established because we want to use this as a model of what happens in current controversies.

We believe that the most constructive discussions will turn on the question of contemporaneous versus retrospective history of science. The purpose served by 
each approach needs to be drawn out. We look forward to developing the analysis alongside our new colleagues.

\section{H. M. Collins}

KES (Centre for the Study of

Knowledge, Expertise and Science),

University of Southampton,

Southampton SO17 1BJ, UK

e-mail:h.m.collins@soton.ac.uk

Trevor Pinch

Program on Science, Technology and Society, 632 Clark Hall, Cornell University,

Ithaca, New York 14853-2501, USA

Sir - We welcome the tone of Gottfried and Wilson's assessment of what they (not we) call 'Edinburgh school' sociology of scientific knowledge ${ }^{1}$. Their eschewal of the ad hominem attacks that have characterized too much of the 'Science Wars' debate is refreshing.

Three points of clarification are, however, in order. First, the goal of the sociology of knowledge, in our view, is the explanation of belief, not its evaluation. 'Symmetrical' analysis of the emergence, development and acceptance or rejection of bodies of knowledge does not involve the (absurd) claim that all beliefs are of equal merit. Rather, 'symmetry' implies that current evaluation of the truth or falsity of beliefs should not bias the empirical study of the processes through which knowledge develops. For the historian or sociologist studying nineteenth-century evolutionism, for example, both Darwinism and antiDarwinism stand equally in need of explanation.

Our second point is a simple corollary of the first. Predictive success is, of course, a vital measure of the merit of bodies of knowledge, and an important cause of their acceptance or rejection. But later predictive success cannot be appealed to as a cause of earlier acceptance.

Third, we have always held that satisfactory analysis of the development of knowledge must be multicausal. Causal input from the real world and psychological and social processes are all involved. Scientific knowledge is not a collective fantasy devoid of relation to the real world, but neither is it a simple mirror of reality. The sociology of scientific knowledge stands or falls by the value of the best, empirical, case-studies of these complex questions. We are glad that these casestudies are attracting the attention, however sceptical, of distinguished natural scientists. We benefit from their scrutiny; perhaps they may learn something in return.

\section{David Bloor}

Science Studies Unit,

\section{Donald MacKenzie}

Department of Sociology, University of Edinburgh, 21 Buccleuch Place, Edinburgh EH8 9LN, UK
Sir - Gottfried and Wilson ${ }^{1}$ criticize the Edinburgh school of sociology's contention that scientific knowledge is a communal belief system with a dubious grip on reality. The assessment is based on two points: (a) the neglect of a large body of experimental evidence that constrains scientific knowledge and guides theory and (b) the predictive power of science.

There is another powerful element that exposes the faulty logic of the 'Edinburgh' school: technology. Science constrains possible technology. When the latter (a new device, instrument or system) becomes reality, it validates the specific theories on which it is founded. If scientific knowledge was not an objective description of reality, but merely a social construct, we would not have technological realities such as transistors, microprocessors, personal computers and the Internet, or semiconductor lasers, fibre optics and compact disc players in addition to radios, cars and jets.

It is instructive to examine a few of the thousands of 'food chains' connecting scientific knowledge (the product of hypotheses and experiments converging into a theory) to technology.

Consider lasers and in particular semiconductor lasers, an essential element of long-distance fibre-optic communications. Without the concepts of 